\title{
Doktor Glaus
}

Daniel Schlossberg

\section{«Dr. Glaus hat vorgesorgt, er hat sich ein Ticket}

\section{nach Ganghei besorgt.»}

Er zieht gemütlich an seiner Pfeife. Es ist eine wie auf jenem berühmt gewordenen Bild von René Magritte. Von Michel Foucault präzise analysiert. Ist das Bild «Ceci n'est pas une pipe» eben nicht die Pfeife selbst, sondern das abgebildete Objekt, so ist Doktor Glaus beim Rauchen nicht real, sondern fiktiv, nur eine Beschreibung seiner selbst.
Korrespondenz:

Dr. med. Daniel Schlossberg Bachmattstrasse 53 CH-8048 Zürich

daniel.schlossberg[at]hin.ch
Er erinnert sich, wie er unter seiner Bettdecke sein Transistorradio an sein Ohr hält und in leiser Lautstärke, auf dass er nicht beim verbotenen Lauschen der Radiohitparade ertappt wird, die Ansage von Mister Pop Jürg Marquard hört: «Platz drei In the year twenty five twenty five> von Zager and Evans.» Es sollte ihr einziger Hit bleiben. Jetzt in diesem Jahr angekommen, auf die siebzig Lenze zusteuernd, hat er sein Reich, die letzte Bastion mit allem, was er hat, verteidigt.

Seine Praxis kann sich des Zulaufs kaum erwehren, er ist der letzte unabhängig tätige Schweizer Arzt. Das Gesundheitswesen wurde von schlitzohrigen Investoren klammheimlich aufgekauft. Nun kann man sich für die Massenwanderungen aufs Matterhorn und das Jungfraujoch, wenn man sonst nicht mehr so gut mithalten mag, mit Akku Punktur behandeln lassen. 800 bis 1000 Ladezyklen garantiert, lassen sich solvente Klienten, anstatt die Haare zu färben, um jung zu erscheinen, gleichsam auf Topleistung trimmen. Oben angekommen, werden teure Gadgets angeboten und mit unheimlich anmutendem Erfolg abgesetzt. Die Geschäfte da oben gehören denselben Investoren.

Dr. Glaus sitzt da unten in seiner Praxis und weiss: Heute behandelt er seinen letzten Fall. Er könnte weitermachen, aber er hat immer gesagt: Wenn es ihm schwerfällt, die Dinge noch korrekt auf seiner Festplatte abzuspeichern, dann ist es Zeit, aufzuhören.

Sein letzter Fall hat sich vorgestern angemeldet er leide an Gelbsucht. Als er in der Praxis erscheint, korrigiert Dr. Glaus dessen Einschätzung mit einer Blickdiagnose: Sein Problem sei die Geltungssucht, das Streben nach Macht und seine Gier, immer noch mehr zu kontrollieren. Der letzte Fall ist gekommen, um die Praxis von Dr. Glaus zu übernehmen. Es ist eine kampflose und dennoch feindliche Übernahme. Der vermeintlich Gelbsüchtige zieht seine Brieftasche hervor und stellt einen Scheck aus. Der Lebensabend von Dr. Glaus ist gesichert. Das Schweizer Gesundheitswesen ist nun komplett in der Hand der Invasoren. Der Innenminister lässt sich die Bedingungen diktieren, unter denen Versicherte in diesem Land eine Behandlung in Anspruch nehmen können. Ruth Dreifuss würde sich im Grab umdrehen, läge sie in einem. Aber sie muss sich eins zu eins im diesseitigen Leben mit ansehen, wie ihr Lebenswerk zerstört wird. Das Wort Solidarität ist aus dem Vokabular gestrichen, Profitmaximierung ist der einzige Zweck des medizinischen Dienstleistungsangebots.

Dr. Glaus zieht an seiner Pfeife, er ist nicht verbittert, längst hat er resigniert. Es hat sich schon früh nach der Jahrtausendwende abgezeichnet, dass der medizinische Nachwuchs zur Sicherstellung der Grundversorgung der Bevölkerung fehlt. Allerorten sind medizinische Zentren in Händen von Versicherern und anderen profitorientierten Unternehmen wie Pilze aus dem Boden gesprossen. Aber diese Konglomerate, diese kleinen Machtballungen wurden von den Invasoren plattgewalzt. Gegen diese geballte Kraft gab es kein erfolgreiches Anstemmen. Dr. Glaus hat vorgesorgt, er hat sich ein Ticket nach Ganghei besorgt. Denn er möchte in Würde abtreten, wenn es so weit ist.

Dr. Glaus nimmt noch einen letzten Zug, dann erlischt die Pfeife und mit ihr Dr. Glaus. Vielleicht war er nie real, immer nur eine Fiktion, so wie die Idee von der Gleichheit in der Medizin.

Dies ist der letzte Fall von Dr. Glaus: Auf den ersten Blick gesund, doch dieser Mensch ist bedroht durch Geltungssucht, Gier und Machtstreben.

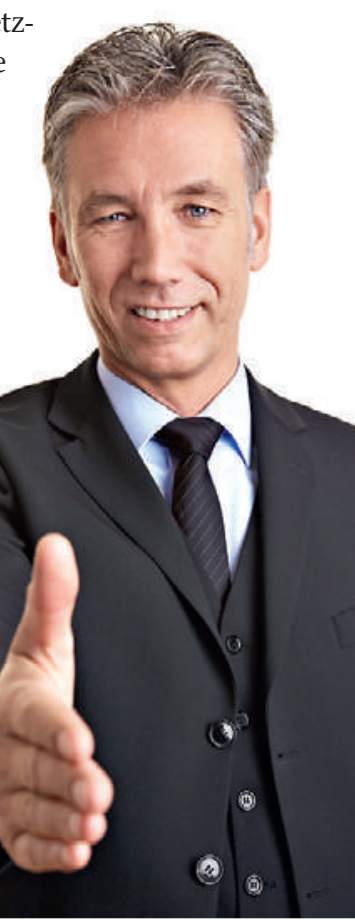

